\title{
Detection of Damage in Spot Welded Joints Using a Statistical Energy Analysis-like Approach
}

\author{
Achuthan C. Pankaj \\ CSIR-National Aerospace Laboratories, Bangalore, 560017, Karnataka, India \\ Department of Mechanical Engineering, National Institute of Technology Karnataka, Surathkal, Mangalore, \\ 575025, India
}

Marandahalli V. Shivaprasad

CSIR-National Aerospace Laboratories, Bangalore, 560017, Karnataka, India

\begin{abstract}
S. M. Murigendrappa
Department of Mechanical Engineering, National Institute of Technology Karnataka, Surathkal, Mangalore, 575025, India
\end{abstract}

(Received 16 August 2016; accepted 12 October 2016)

Vibration-based damage detection has been frequently used for low frequency problems. However, there are situations where the damage, like connections of structures with spot welds, mainly affects the highest modes. Energybased approaches such as Statistical Energy Analysis (SEA) is one of the most widely used methods for high frequency analysis that is well-suited for periodic structures. The present work studies the damage detection of joints based on statistical energy analysis-like principles using apparent coupling factors to predict velocity/acceleration responses and detect damage in the spot welds located at various positions on a sub-system (spot-welded plate configurations). Apparent coupling factors have been derived for four cases of spot-welded plates and used further to predict the velocity/acceleration responses using the statistical energy analysis like (SEAL) approach for an assembly of three subsystems (three plates lap joined by spot-welds) for all the possible combinations. The results are discussed, compared, and validated by experimentation and finite element simulations for a healthy and damaged configuration. A database of the predicted values using the SEAL approach for the remaining combinations has been compared with values obtained from finite element simulations. The proposed SEAL-based approach can be effectively applied as a simulation tool to locate the damaged joint in an assembly of subsystems for future use.

\section{INTRODUCTION}

Vibration-based health monitoring has been frequently used for low frequency problems. ${ }^{1}$ However, there are situations and problems wherein the damage affects mainly the highest modes, rather than the lowest, such as connections of structures with cleats/spot welds etc. ${ }^{2}$ Structural health monitoring techniques based on identifying the damaged samples (delamination) by shifts in the frequencies of some of the vibration modes has been carried out by exciting the samples at high frequencies using lead zirconate titanate (PZT) piezoelectric elements acting as sensors and actuators. ${ }^{3}$ Similarly, the use of the electro-mechanical impedance signatures of piezoelectric wafer active sensors (PWAS), which are permanently mounted to the structure along with a probabilistic neural network (PNN), to classify the spectral data and identify the severity of damage has been used in the health monitoring of thin plates and aerospace structures. ${ }^{4}$ Pattern recognition methods based on neural networks and support vector machines have also been used for damage detection. ${ }^{5,6}$ The main challenge with these methods is that if the structure is considered undamaged in its current state, data from the damaged class is not available unless some simulated finite element/experimental models can be used to generate data for the damaged class.

New advanced instrumentation like the scanning laser vibrometer and motion magnification approaches has motivated the development of damage identification methods based on higher-frequency vibrational responses. Nevertheless, unlike finite element methods used at low-frequencies, energy-based approaches like SEA is one of the widely used methods in the high frequency regime that is well-suited to periodic structures. The application of SEAL approaches and parameters like apparent/effective coupling loss factors/energy influence coefficients between sub-elements can be used to detect and localize the damage.

The present paper presents the studies of damage detection of spot-welded joints based on SEAL principles and effective coupling factors derived from experiments and finite element simulations. Apparent coupling factors has been derived for four cases of two spot-welded plates and used further to predict the velocity/acceleration responses using the SEAL approach for an assembly of three subsystems (three plates lap joined by spot-welds). The outcomes acquired have been examined and validated by experimentation and finite element simulations for a healthy and damaged configuration. Further, a database 


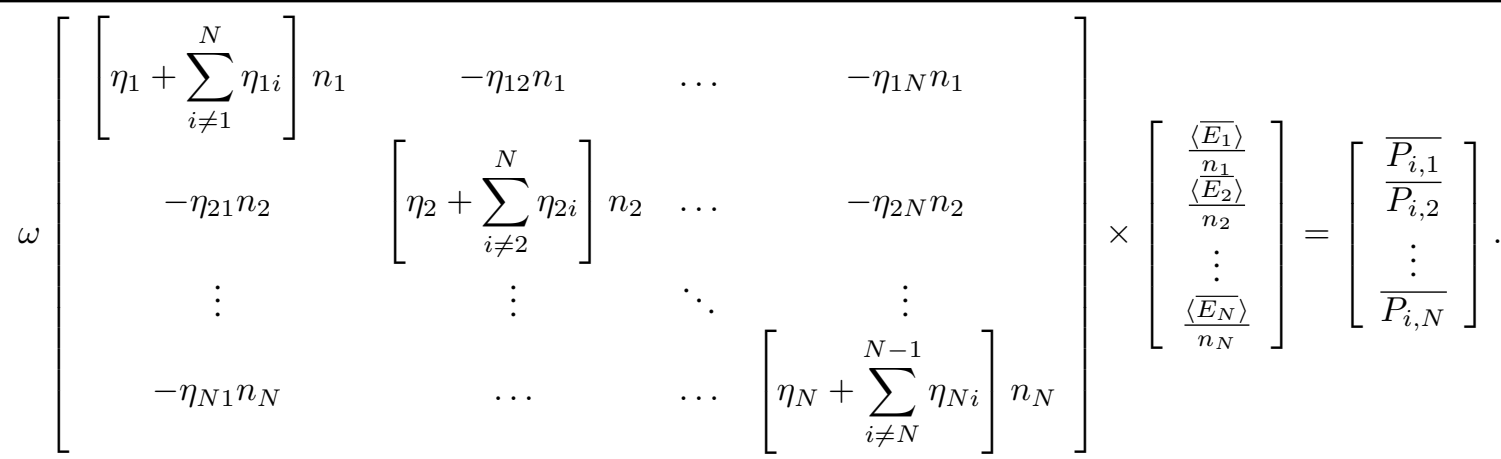

of the predicted values using the SEAL approach for remaining combinations has been compared with values obtained from finite element simulations. The proposed SEAL-based prediction approach can thus be used to generate a database of velocity/acceleration responses for various possibilities of sequentially coupled combinations of the basic cases, which can be effectively applied to locate the damaged joint in an assembly of subsystems for future use. The authors propose the use of the SEAL approach as a simulation tool for prior prediction and generation of a database of the joint damage scenarios for a structural assembly of sub-systems. The data generated can also be further utilized for optimal location of sensors and pattern recognition methods for damage detection.

Mild steel plates have been used in the present work that have low values of material damping. The coupling loss factor (CLF) computed by the wave approach is independent of the internal loss factor as compared to the values computed using finite element method, wherein CLF increases linearly as the internal loss factor varies from a zero value, followed by a transition region and converges to the values obtained by the analytical wave approach at higher frequencies. ${ }^{7,8}$ The finite element modeling of spot-welded joints requires easyto-connect congruent as well as non-congruent meshes and to locate weld nuggets anywhere in the meshes. For this purpose, Area Contact Model 2 (ACM2) and CWELD are widely used finite element models in the automotive industry. ${ }^{9}$ In the present study, a finite element model of spot welds has been modelled as an ACM2 model using ANSYS software. The modelling of discrete joints like the spot welded joints in computation of the coupling factors is significant in terms of its further use in computation of energies and velocity responses using statistical energy approach. ${ }^{10}$ SEA involves predicting the vibration response of a complex structure by dividing it into a number of subsystems. In predictive SEA, coupling and damping loss factors are estimated through experiments, analytical, and numerical approaches by solving the power balance equations Eq. (1) (see top of the page), where $\left\langle E_{i} / n_{i}\right\rangle$ are the modal energy (energy per mode) of subsystem $i$ and $n_{i}$ is the modal density of subsystem $i$. The power injected in subsystem $N$ is $P_{i N}$, frequency averaging has been denoted by a - $\left\langle E_{i}\right\rangle$ is the spatially averaged energy in subsystem $i$ and $\omega$ central band frequency, $\eta_{i}$-internal damping loss factor in subsystem $i$ and $\eta_{i j}$ is coupling loss factor (CLF) from subsystem $i$ to subsystem $j$.

The energies in all the subsystems are computed for the corresponding power to the respective sub-system, with known ma-

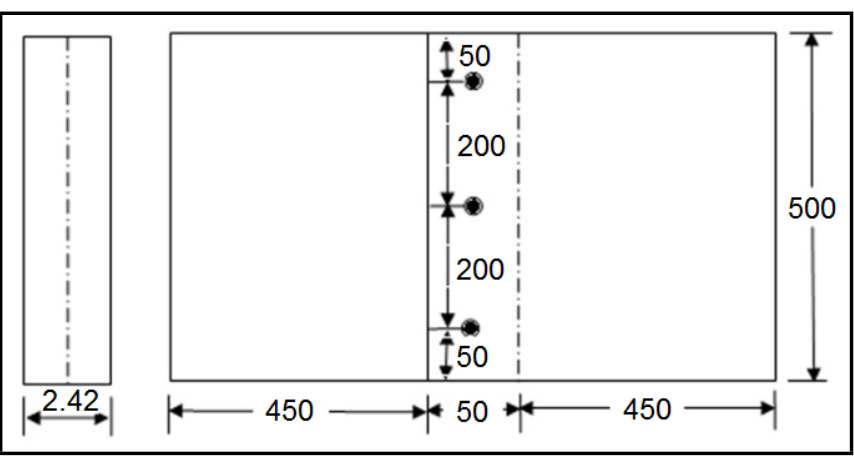

Figure 1. Geometric dimensions of plates with spot-welds (case-1).

terial damping and the coupling factors can then be found out by the matrix inversion approach and vice versa. Equation (1), which is a SEA equation, relates ensemble average powers and energies, whereas the simulated FE results are based on a single estimate of frequency average quantities. In the present paper, the focus is on using the energy flow balance for the individual cases, based on the principles of SEA and not applying its underlying assumptions and procedural rules of analysis. The coupling loss factor estimated in this manner has been referred to as an apparent coupling loss-factor (ACLF) or Energy Influence Coefficient (EIC) and the term SEA-like (SEAL) approach has been adopted to distinguish between SEA and the use of the energy flow balance in SEA as applied in the energy flow model. ${ }^{11}$ The variance of the ACLF / EICs generally decreases as modal overlap or the number of modes in the band increase. $^{12}$

\section{TEST SPECIMENS}

The dimensions of each plate considered in the studies are $500 \mathrm{~mm} \times 500 \mathrm{~mm} \times 1.2148 \mathrm{~mm}$, made of mild steel. The plates have been joined by spot welds with an overlap length between two sheets of $50 \mathrm{~mm}$. Three spot welds are lined up on the centre of the overlap in a longitudinal direction and in a transverse direction, one of the three spot welds is centrally located and the others are located $50 \mathrm{~mm}$ away from the edge of the plate shown in Fig. 1. The diameters of the spot weld nuggets are approximately $6 \mathrm{~mm}$. The density of the mild steel plates has been assumed to be $7850 \mathrm{~kg} / \mathrm{m}^{3}$ with a modulus of elasticity of $210 \mathrm{GPa}$. The following cases of two plates joined by spotwelds have been considered to obtain the apparent coupling factors using the SEAL approach.

- Case-1: Two plates with lap joint having three spot welds 
(Healthy Configuration)

- Case-2: Two plates with lap joint having two spot welds (Centre weld assumed to be damaged)

- Case-3: Two plates with lap joint having two spot welds (Bottom most weld assumed to be damaged)

- Case-4: Two plates with lap joint having one spot weld at the Centre (Two extreme spot welds assumed to be damaged)

\section{EXPERIMENTAL SETUP}

The experimental setup consists of spot-welded plates to be tested, data acquisition hardware, sensors, shakers, and computer with modal analysis software as shown in Fig. 2. SCADAS III is a multichannel 24 bit data acquisition system with inbuilt ADC and signal conditioners for ICP type of accelerometers. Communication between the data acquisition hardware and computer system is established through SCASI card. Laptop with advanced modal analysis software LMS Test lab is used for data acquisition, analysis, and extracting the modal parameters. ICP based PCB make accelerometers with sensitivity of $100 \mathrm{mV} / \mathrm{g}$ (Model No. 333B30) has been used for acceleration response measurement. Electrodynamic shakers of Bruel and Kjaer with a force rating of $200 \mathrm{~N}$ sine (Type 4825 ) with an excitation frequency limitation beyond $3000 \mathrm{~Hz}$ and a compatible power amplifier has been used to excite the plate and the excitation force is measured using force transducer with a sensitivity of $500 \mathrm{mV} / \mathrm{N}$ and force range of $44 \mathrm{~N}$. The maximum excitation frequency for the experiments has been limited to $3000 \mathrm{~Hz}$. The spot welded plates have been hung by strings to simulate a free-free boundary condition. The geometry as per the test points chosen for measurements have been created in the LMS test lab. Each plate has been divided equally into nine regions and the responses have been obtained using nine accelerometers placed centrally for each of the region. The nodes i.e., the accelerometer positions and wire frame geometry created has been shown in Fig. 3. The channels setup was carried out with setting type of sensor, excitation voltage, units, reference point, measurement point IDs, and gain settings. To compute the natural frequencies, scope settings with maximum frequency was set to $512 \mathrm{~Hz}$ and spectral lines of $2622 \mathrm{~Hz}$, which gave a frequency resolution of $0.19 \mathrm{~Hz}$. Uniform windows were chosen for both excitation and response signals. A 50\% burst random signal has been used for exciting the plate. Same scope settings are imported to test setup and required functions such as time domain data, cross power spectrums, peak spectra, FRF, and auto power spectra etc. are selected to store into the computer database. In case of harmonic sinusoidal excitation and acceleration response measurement $32768 \mathrm{~Hz}$ sampling frequency and maximum bandwidth of $10000 \mathrm{~Hz}$ has been set.

\section{POWER INJECTION METHOD}

In coupled sub-systems, the power injection method (PIM) involves the measurement of energy for each subsystem for the

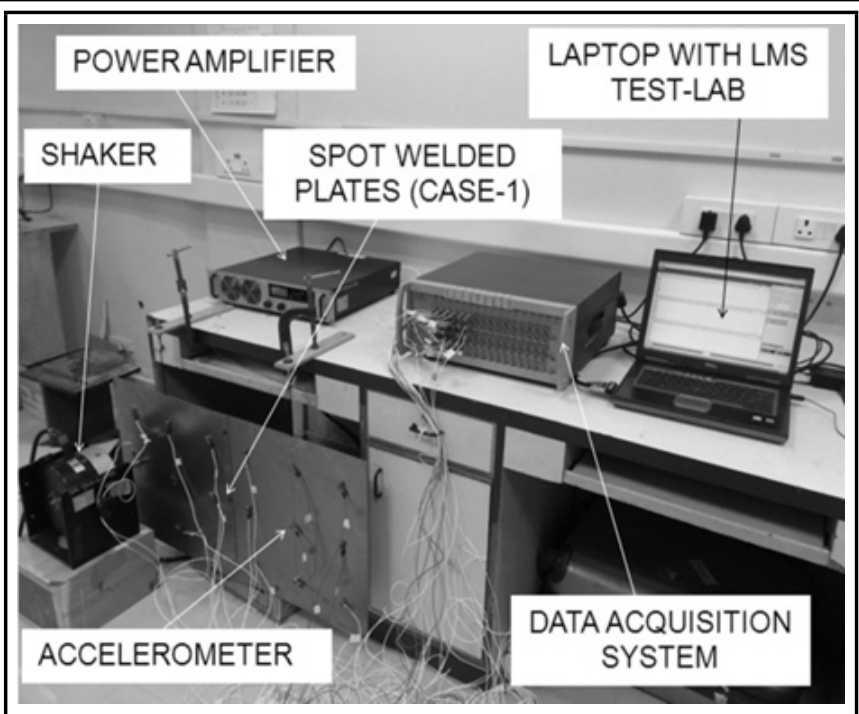

Figure 2. The experimental set-up.

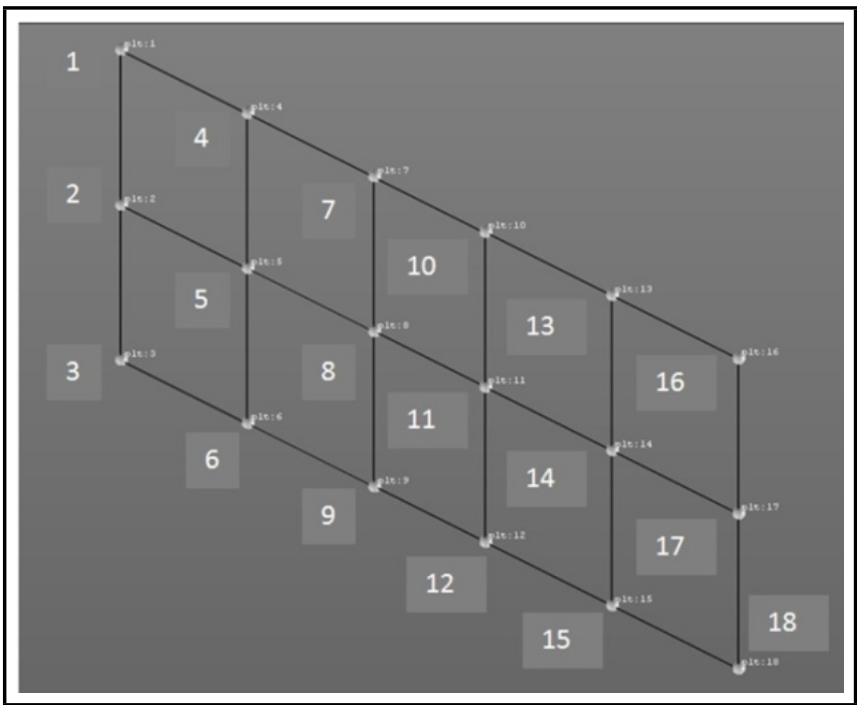

Figure 3. The geometry of the two-spot welded plates created in Test-lab.

power input into every single subsystem and its corresponding measurement. Subsequently the SEA parameters, like internal loss and coupling loss factor, can be obtained by inversion of the measured energy matrix. ${ }^{13}$ The time averaged power input into a subsystem ${ }^{14}$ is given as:

$$
P=\frac{1}{\omega} \operatorname{Im}\left(S_{a f}(\omega)\right) .
$$

Power input measurements $(P)$ requires the evaluation of the imaginary part of the cross spectrum $S_{a f}$. PIM is based on a comparison of the dissipated energy of a system to the total energy of the system $\left(E_{\text {Total }}\right)$ under steady state vibration. Since the power input $(P)$ into a single system is dissipated by the system under steady state conditions, the dissipated power can be replaced with the power input (Eq. (3)) to obtain the internal loss factor at a particular excitation frequency. ${ }^{15}$

$$
\eta=\frac{P}{\omega E_{\text {Total }}} .
$$

Excitation was carried out at discrete frequencies of 1000 to $3000 \mathrm{~Hz}$ in steps of $500 \mathrm{~Hz}$. The test was repeated for 3 to 4 


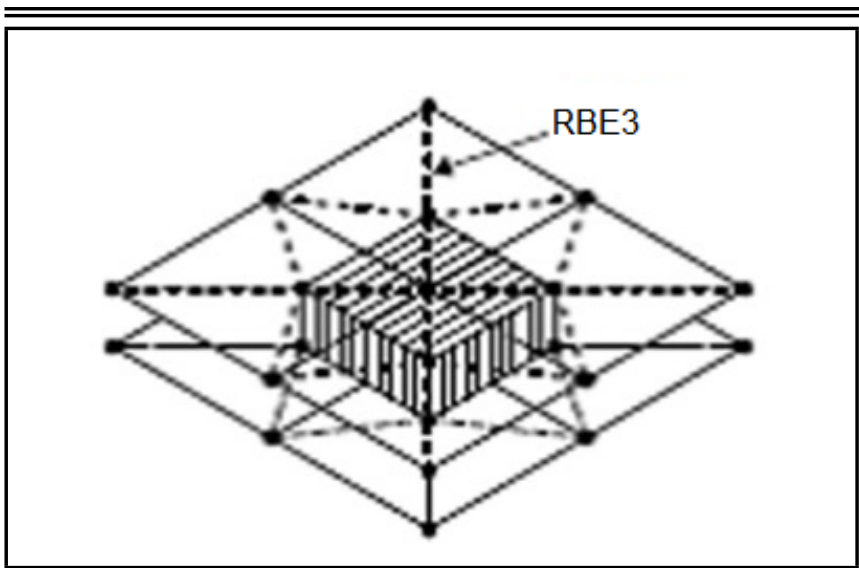

Figure 4. A diagram of ACM2 (Spot welded joint) model.

trials in each case. The input excitation force was applied on the centre $(0.25 \mathrm{~m}, 0.25 \mathrm{~m})$ of one plate (Pt-5, Fig. 3). The plate was excited for flexural vibratory modes.

\section{FINITE ELEMENT ANALYSIS}

Simplified models of spot welds in FEA have been created using shell elements for the plates and using a single solid element or beam element for the weld nuggets. The most commonly used finite element models in the industry are the CWELD and the area contact model (ACM2) models. ${ }^{16,17}$ The ACM2 model consists of a single solid element (shaded cuboid) connecting the upper and lower shell elements with constraint elements. Each node of the solid element is connected to four nodes of one shell element via constraint equation elements shown in Fig. 4. The patch for the ACM2 model consists of four shell elements for each of the two sheets. The rigid body element (RBE3) is an interpolation element that forms constraint equations and is used to distribute force/moment from master node to slave nodes proportional to the weighting factors.

The spot weld nuggets have been modelled using solid elements (SOLID185 with $6 \mathrm{~mm}$ square and $1.2148 \mathrm{~mm}$ high), that is the ACM2 model. The natural frequencies and the mode shapes have been computed under the free-free boundary conditions. The upper and lower plates have been meshed using SHELL63 elements with a mean mesh size of $6 \mathrm{~mm}$ (Fig. 5). Shell 63 has both bending and membrane capabilities. The finite element method calculations were carried out using element dimensions smaller than one-sixth of the bending wavelength. The patches have been meshed with $6 \mathrm{~mm}$ square shell elements, while areas along the edges are meshed with less than $6 \mathrm{~mm}$ non-square elements. In addition, for the ACM2 model, the centre of the patch area is coincident with the centre of solid element. The damaged spot welds have not been modelled representing the stiffness loss for a spot welded joint at that particular location. Dynamic analysis of the FE model of the spot-welded plates has been carried out for a free-free condition and the dynamic frequency spectrum has been obtained by invoking the lanczomethod in ANSYS, with unit mass criteria for normalizing mode shapes.

The full method available in ANSYS has been used for the harmonic analysis. A harmonic force with unit load intensity

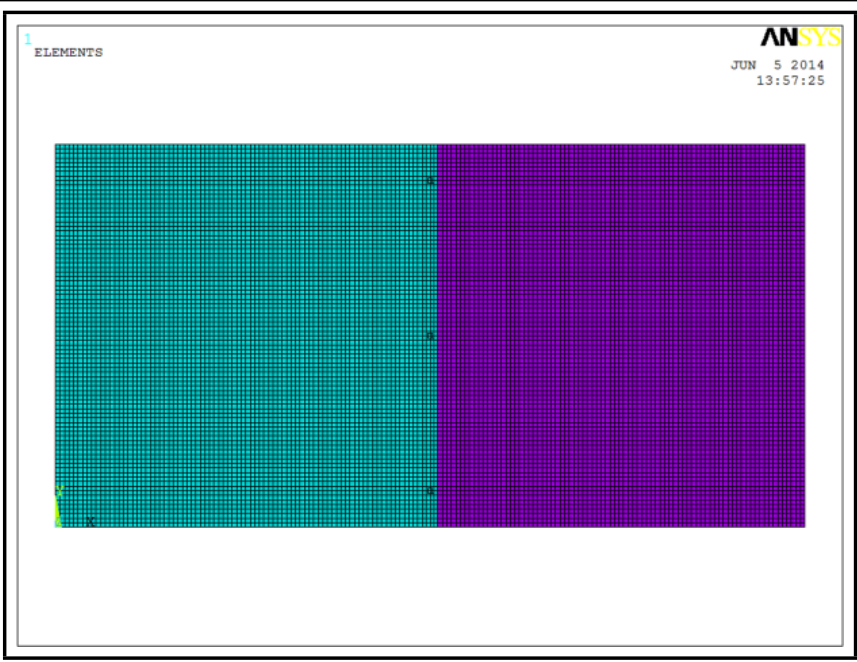

Figure 5. The finite element model (case-1).

has been applied in the range of frequencies of $1000-3000 \mathrm{~Hz}$ at steps of $500 \mathrm{~Hz}$. A unit force of $1 \mathrm{~N}$ was applied on the first plate and the velocity responses on both the plates were computed. The internal loss factors estimated by the experimental power injection method on a single plate for different frequencies have been used for the finite element simulation at the respective frequencies. The mass of the accelerometers ( $5 \mathrm{gms}$ ) has been modelled as a concentrated mass element (mass 21) at the locations wherein the accelerometers have been placed during the experiments. The additional mass of the force transducer (10 gms) has also been included in the concentrated mass element (mass 21 element) at the point of excitation force.

The velocity responses at the nodes of the plates, wherein responses have been obtained in the experiments, including the power input location has been determined. Macros have been developed in ANSYS Parametric Design language (APDL) for post-processing and computation of power input and velocities. Finally the energy $\left(E_{i}\right)$ of each region of the plate estimated by using Eq. (4), wherein $\left(M_{i}\right)$ is the mass of one of the 9 regions on each plate and the representative subsystem velocity $\left(V_{i}\right)$ corresponding to that region.

$$
E_{i}=\frac{M_{i} V_{i}^{2}}{2} .
$$

The total energy of each plate has been computed by the summation of the energies obtained from individual regions of that plate $\left(E=E_{1}+E_{2} \ldots E_{9}\right)$. The apparent coupling factors have been computed by the matrix inversion approach from Eq. (1) after computation of power inputs and corresponding energies of each plate. The maximum average velocity response of each plate has been obtained directly from the postprocessing of the output results. The codes for post-processing the responses, energies have been developed in the parametric design language available in ANSYS and MATLAB software.

\section{RESULTS AND DISCUSSION}

The comparison of the natural frequencies obtained from the finite element analysis and experiments for few of the elastic modes of case- 1 (healthy configuration) has been shown in Table 1 . It can be observed that the maximum error is within an 


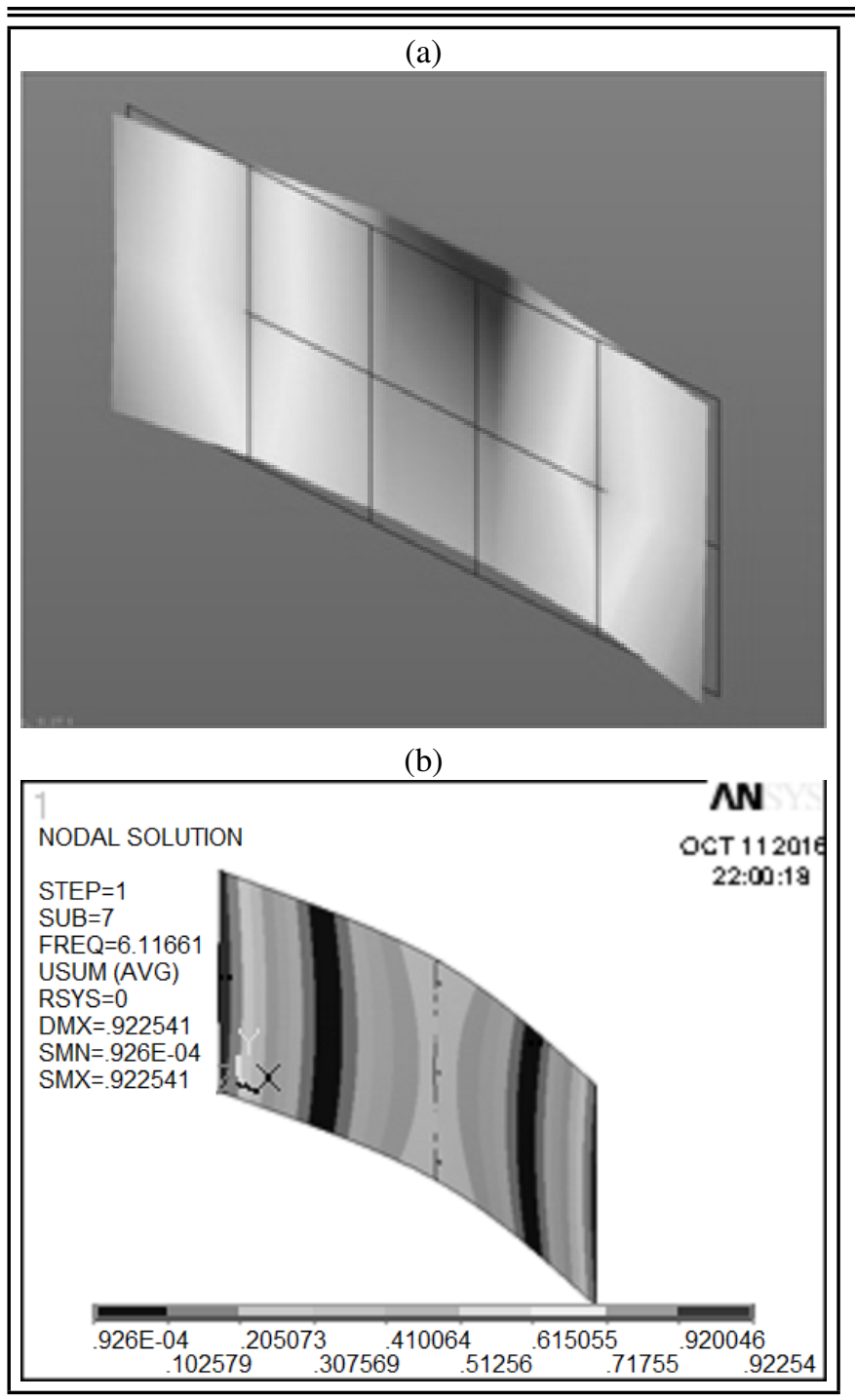

Figure 6. Comparison of the Experimental and FEM mode shapes (Mode. No-7).

acceptable range of 5\%. Figures 6 and 7 shows the comparison of two typical mode shapes obtained from the finite element analysis and experiments for case-1. Similar trends have been observed for the other cases.

The acceleration responses have been obtained from the defined locations by experimentation on the plates. The last column of Table 2 shows the sinusoidal force excitation values at the excitation point on the plate. The responses and the excitation force being sinusoidal in nature, the maximum value obtained are computed by post-processing the values in MATLAB software. The maximum acceleration responses obtained at all the points on both the plates is divided by the maximum excitation force to obtain the acceleration responses for unit excitation loading of $1 \mathrm{~N}$ as shown in Table 3 .

The acceleration responses have been divided by the excitation frequency to obtain the velocity responses. The vibratory energies in the plates have been computed based on Eq. (4). The power injected at the excitation location has been obtained from the cross-spectrum of force and acceleration by Eq. (2). Finally the apparent coupling factors have been computed by the inversion of power balance equation as given in Eq. (1). The apparent/effective coupling factors $\left(\eta_{12}=\eta_{21}\right)$ for all the

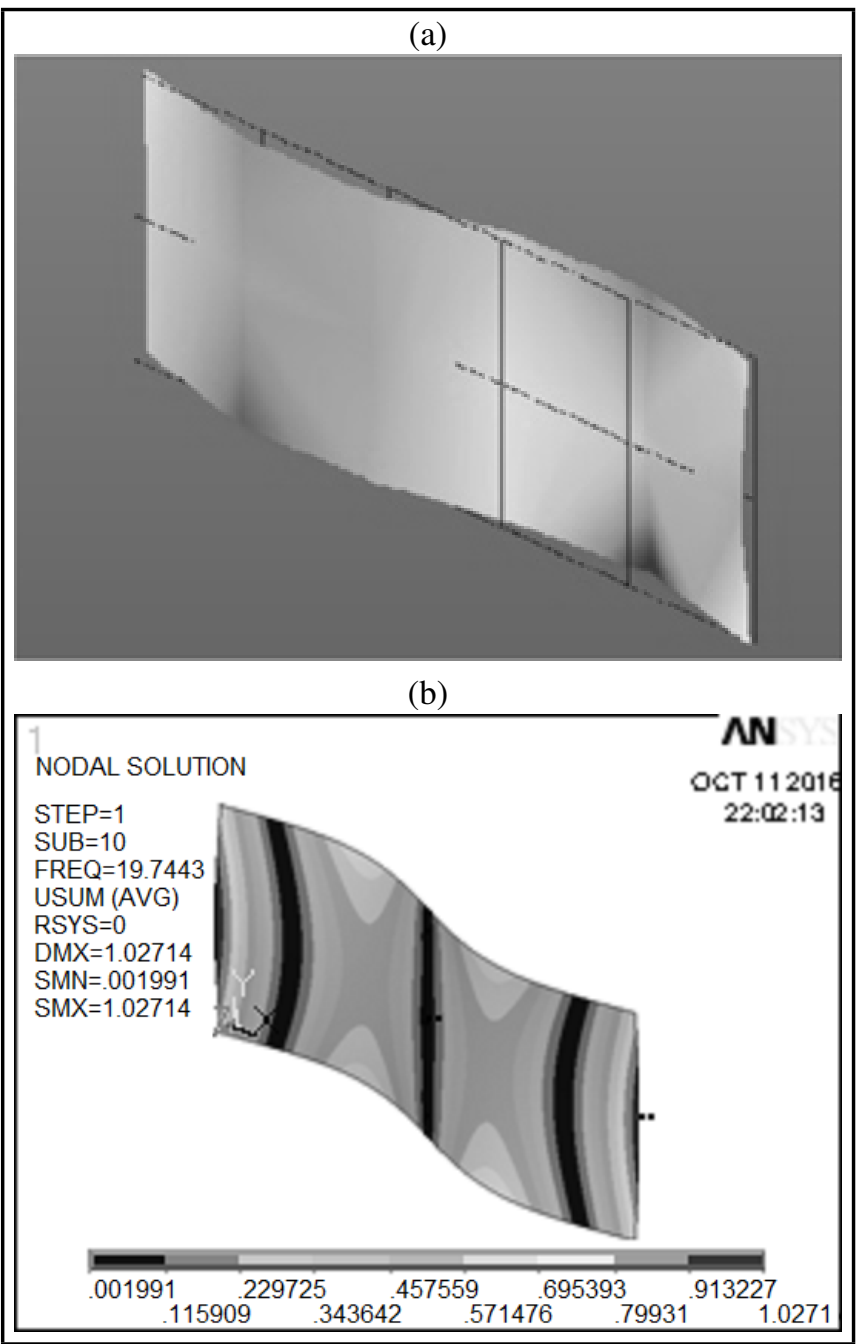

Figure 7. Comparison of the Experimental and FEM mode shapes (Mode. No-10).

Table 1. Natural frequencies comparison for elastic modes (Case-1).

\begin{tabular}{|c|c|c|c||}
\hline Mode No. & FEM (Hz) & Experimental $(\mathbf{H z})$ & \% Error \\
\hline 7 & 6.1166 & 5.98 & 2.28 \\
\hline 8 & 8.198 & 8.01 & 2.34 \\
\hline 9 & 17.403 & 16.8 & 3.58 \\
\hline 10 & 18.744 & 18.5 & 1.31 \\
\hline 11 & 27.474 & 28.9 & 4.93 \\
\hline 12 & 31.456 & 31.25 & 0.65 \\
\hline 13 & 31.867 & 31.5 & 1.16 \\
\hline 14 & 35.07 & 36.7 & 4.44 \\
\hline 15 & 44.546 & 45.5 & 2.09 \\
\hline 16 & 47.516 & 49.02 & 3.06 \\
\hline 17 & 60.62 & 59.5 & 1.88 \\
\hline 18 & 62.625 & 62.5 & 0.2 \\
\hline 19 & 72.231 & 71.29 & 1.31 \\
\hline 20 & 76.313 & 76.23 & 0.10 \\
\hline
\end{tabular}


Table 2. Sample acceleration responses (Case-1).

\begin{tabular}{||c|c|c|c|c|c||}
\hline \multirow{2}{*}{$\begin{array}{c}\text { Time } \\
(\text { secs})\end{array}$} & \multicolumn{4}{|c|}{ Acceleration Response (g) } & Force \\
\cline { 2 - 5 } & Node-1 & Node-2 & $\vdots$ & Node-18 & \\
\hline 4.9999762 & 9.74 & -24.1 & $\vdots$ & 3.28 & -8.73 \\
\hline 5.0000067 & -13.1 & -24.5 & $\vdots$ & -10.8 & -8.04 \\
\hline 5.0000372 & -31.2 & -17.2 & $\vdots$ & -21.1 & -4.76 \\
\hline$\vdots$ & $\vdots$ & $\vdots$ & $\vdots$ & $\vdots$ & $\vdots$ \\
\hline$\vdots$ & $\vdots$ & $\vdots$ & $\vdots$ & $\vdots$ & $\vdots$ \\
\hline 5.0999823 & 5.32 & -24.8 & $\vdots$ & 0.363 & -8.81 \\
\hline 5.1000128 & -17.2 & -23.5 & $\vdots$ & -13.4 & -7.55 \\
\hline
\end{tabular}

Table 3. Acceleration responses for unit force (1 N) (Case -1).

\begin{tabular}{||c|c|c|c|c|c||}
\hline \multicolumn{4}{|c|}{ Acceleration Response (g) } & \multirow{2}{\text{Force}}{$\begin{array}{c}\text { Excitation } \\
\text { Location }\end{array}$} \\
\hline Node-1 & Node-2 & & Node-18 & (N) & 1 \\
\hline 4.5011 & 2.8571 & $\ldots$ & $\ldots$ & 2.7098 & 1 \\
\hline
\end{tabular}

cases of the spot-welded plates obtained from finite element analysis and experiments has been listed out in Table 4 and Table 5 respectively. Similarly, the velocity responses obtained by both the methods for all the cases under consideration have been compared in Figs. 8 to 11. The internal loss factor $\left(\eta_{12}\right)$ for two coupled plates of the same size and material with an internal loss factor $(\eta)$ can be also directly obtained from Eq. (5), wherein $E_{11}$ is the energy in plate 1 and $E_{12}$ is the energy in plate 2 , when plate 1 is excited. $E_{22}$ is the energy in plate 2 and $E_{21}$ is the energy in plate 1 , when plate 2 is excited.

$$
\eta_{12}=\frac{\eta E_{21}\left(E_{22}+E_{12}\right)}{\left(E_{11} E_{22}+E_{12} E_{21}\right)} .
$$

The graphs reveal that the variation in the velocity responses obtained from experimental and FE simulations reduces with the increase in excitation frequencies. At low frequencies, due to reduction in modal overlap, there can be inaccurate assumptions in the energy balance equations in SEA approach. At higher frequencies, the excitation frequency selected, would have equivalent energies as generated by its accompanying modes representing a uniform energy density in a particular bandwidth due to higher modal overlap. Excitation frequencies that generate sudden peak responses as observed near $1500 \mathrm{~Hz}$ is undesirable for the present studies, as small perturbations around it may lead to a large variation in output responses. The theoretical value of modal density of each plate turns out to be 0.0207 .

The modal overlap factor $(M=\omega \eta n)$ preferred for application of the SEA principle should be greater than 1 . The response signals obtained from experiments has been found to be better at higher frequencies. It had also been observed that the

Table 4. Apparent coupling factors (experimental).

\begin{tabular}{|c|c|c|c|c|c||}
\hline \multirow{2}{*}{ Case- no. } & \multicolumn{5}{|c|}{ Frequency (Hz) } \\
\cline { 2 - 6 } & $\mathbf{1 0 0 0}$ & $\mathbf{1 5 0 0}$ & $\mathbf{2 0 0 0}$ & $\mathbf{2 5 0 0}$ & $\mathbf{3 0 0 0}$ \\
\hline 1 & $1.6 \mathrm{e}-3$ & $1.46 \mathrm{e}-3$ & $3.0 \mathrm{e}-4$ & $1.2 \mathrm{e}-3$ & $1.8 \mathrm{e}-3$ \\
\hline 2 & $3.4 \mathrm{e}-4$ & $8.7 \mathrm{e}-4$ & $1.2 \mathrm{e}-3$ & $1.0 \mathrm{e}-3$ & $8.5 \mathrm{e}-4$ \\
\hline 3 & $3.1 \mathrm{e}-4$ & $9.0 \mathrm{e}-4$ & $1.1 \mathrm{e}-3$ & $1.6 \mathrm{e}-3$ & $6.0 \mathrm{e}-4$ \\
\hline 4 & $1.6 \mathrm{e}-3$ & $1.6 \mathrm{e}-3$ & $1.0 \mathrm{e}-4$ & $3.0 \mathrm{e}-4$ & $4.0 \mathrm{e}-4$ \\
\hline
\end{tabular}

(a)

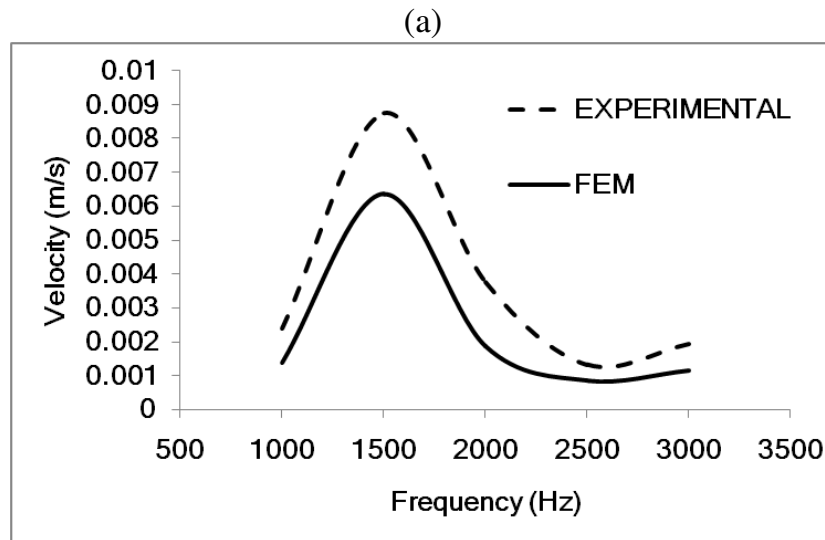

(b)

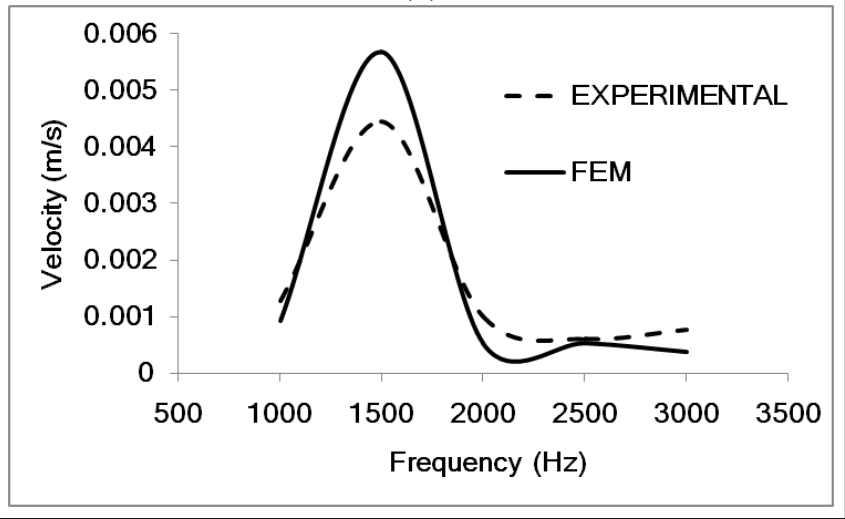

Figure 8. Velocity responses for case 1 (a) Plate 1 and (b) Plate 2.

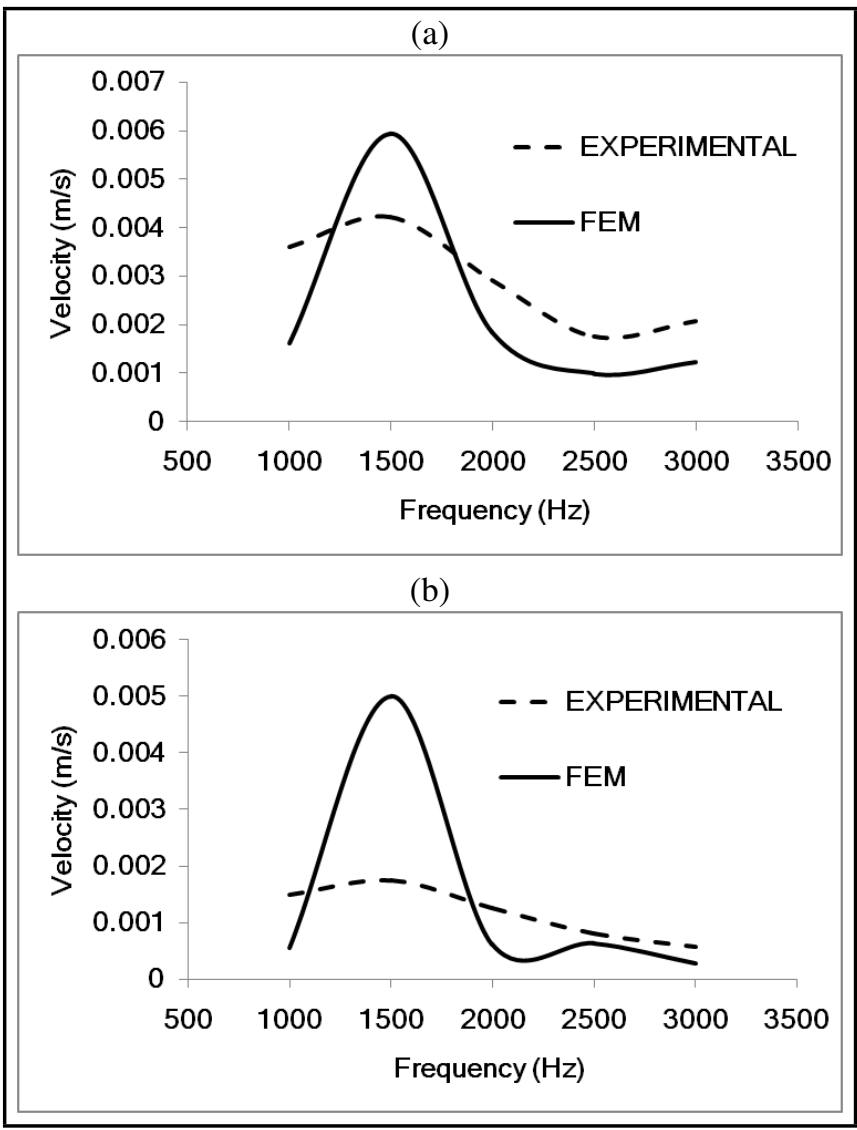

Figure 9. The velocity responses for case-2 (a) Plate 1 and (b) Plate 2. 


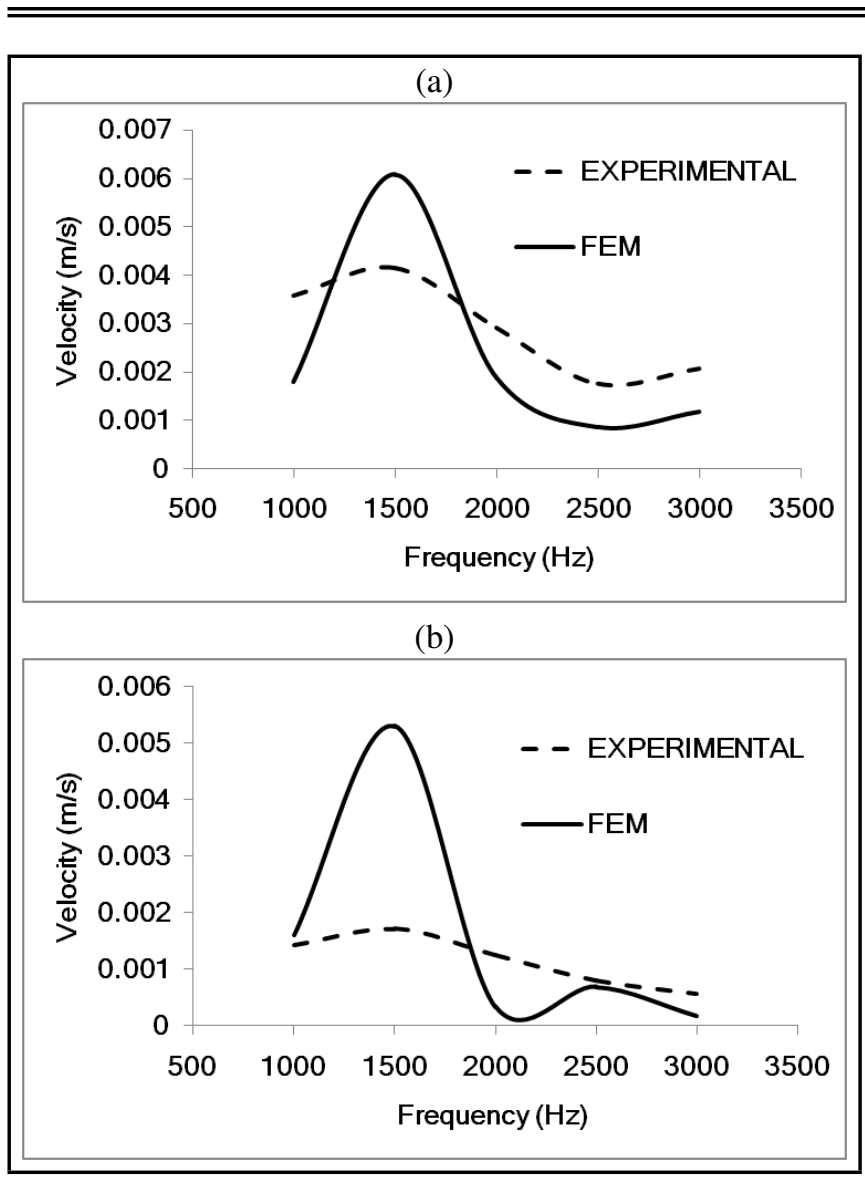

Figure 10. Velocity responses for case 3 (a) Plate 1 and (b) Plate 2.

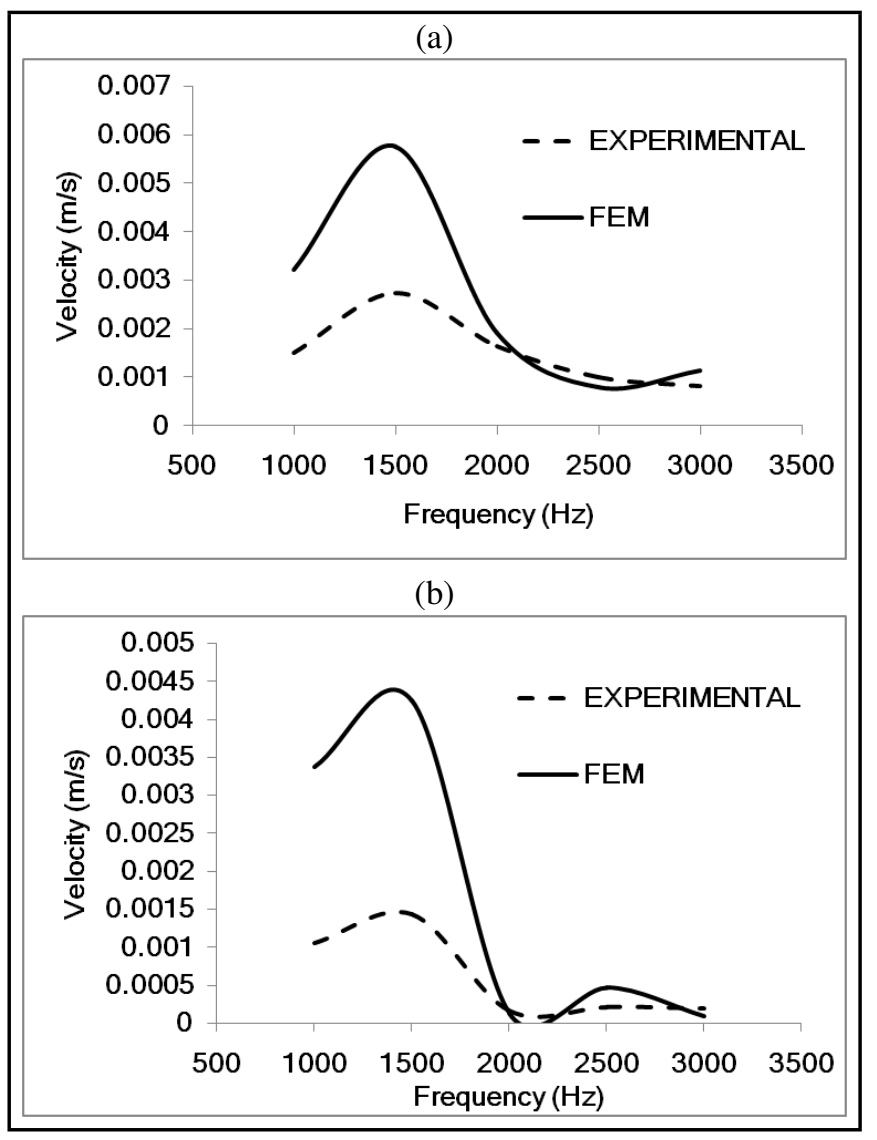

Figure 11. The velocity responses for case-4 in (a) Plate 1 and (b) Plate 2.
Table 5. Apparent coupling factors (FEM).

\begin{tabular}{|c|c|c|c|c|c||}
\hline \multirow{2}{*}{ Case- no. } & \multicolumn{5}{|c|}{ Frequency (Hz) } \\
\cline { 2 - 6 } & $\mathbf{1 0 0 0}$ & $\mathbf{1 5 0 0}$ & $\mathbf{2 0 0 0}$ & $\mathbf{2 5 0 0}$ & $\mathbf{3 0 0 0}$ \\
\hline 1 & $1.4 \mathrm{e}-3$ & $1.4 \mathrm{e}-3$ & $5.0 \mathrm{e}-4$ & $3.9 \mathrm{e}-3$ & $1.0 \mathrm{e}-3$ \\
\hline 2 & $2.0 \mathrm{e}-4$ & $2.0 \mathrm{e}-4$ & $7.0 \mathrm{e}-3$ & $2.0 \mathrm{e}-3$ & $5.0 \mathrm{e}-4$ \\
\hline 3 & $6.3 \mathrm{e}-4$ & $1.3 \mathrm{e}-4$ & $2.0 \mathrm{e}-3$ & $9.8 \mathrm{e}-3$ & $4.0 \mathrm{e}-4$ \\
\hline 4 & $-1.8 \mathrm{e}-3$ & $4.9 \mathrm{e}-3$ & $2.5 \mathrm{e}-4$ & $3.2 \mathrm{e}-4$ & $1.0 \mathrm{e}-4$ \\
\hline
\end{tabular}

Table 6. Ratio of velocity responses of Plate 1 and Plate $2(3000 \mathrm{~Hz})$.

\begin{tabular}{|c|c|c|c|c|c|}
\hline \multicolumn{2}{|c|}{ Case } & 1 & 2 & 3 & 4 \\
\hline \multirow{3}{*}{ EXP } & $\begin{array}{c}\text { Plate1 } \\
(\mathrm{P} 1)(\mathrm{m} / \mathrm{s})\end{array}$ & $1.92 \mathrm{e}-3$ & $1.9 \mathrm{e}-3$ & $2.06 \mathrm{e}-3$ & $8.16 \mathrm{e}-4$ \\
\hline & $\begin{array}{l}\text { Plate2 } \\
(\mathrm{P} 2)(\mathrm{m} / \mathrm{s})\end{array}$ & $8.75 \mathrm{e}-4$ & $6.2 \mathrm{e}-4$ & $5.62 \mathrm{e}-4$ & $1.98 \mathrm{e}-4$ \\
\hline & (P1/P2) & 2.19 & 3.06 & 3.66 & 4.12 \\
\hline \multirow{3}{*}{ FEM } & $\begin{array}{l}\text { Platel } \\
(\mathrm{P} 1)(\mathrm{m} / \mathrm{s})\end{array}$ & $1.14 \mathrm{e}-3$ & $1.2 \mathrm{e}-3$ & $1.18 \mathrm{e}-3$ & $1.12 \mathrm{e}-3$ \\
\hline & $\begin{array}{c}\text { Plate2 } \\
(\mathrm{P} 2)(\mathrm{m} / \mathrm{s})\end{array}$ & $4.10 \mathrm{e}-4$ & $3.2 \mathrm{e}-4$ & $2.80 \mathrm{e}-4$ & $1.40 \mathrm{e}-4$ \\
\hline & (P1/P2) & 2.77 & 3.85 & 4.19 & 8.02 \\
\hline
\end{tabular}

variation in the derived coupling factors due to the variation in the excitation force location on the excited plate also reduces with the increase in the excitation frequencies. Table 6 shows the ratio of velocities obtained in plate- 1 and plate- 2 at an excitation frequency of $3000 \mathrm{~Hz}$ for all the cases of two plates joined by spot-welds. The deterministic frequency of $3000 \mathrm{~Hz}$ with an internal modal loss factor of 0.007 has been selected for further damage detection studies in the present work. It can be observed that as the number of spot welds decreases the energies and consequently the velocities in the second plate is reduced considerably and therefore the ratio of velocity responses of plate-1 to plate-2 (P1/P2) increases.

\subsection{Joint Damage Detection}

The studies for damage detection consists of three identical plates coupled in sequence by a simple lap spot welded configuration has been considered for all the possible combinations of the cases as explained in section 2. The statistical energy analysis-like approach has been applied by using the apparent coupling factors in Tables 4 and 5 to predict the velocity responses in the three plates for all the possible combinations, as listed out in Table 7.

The velocity responses for two such combinations, viz.

Table 7. List of possible combinations for three spot-welded plates.

\begin{tabular}{|c|c|c|}
\hline Combination & $\begin{array}{c}\text { Plate-1 } \\
\text { and 2 }\end{array}$ & $\begin{array}{c}\text { Plate-2 } \\
\text { and 3 }\end{array}$ \\
\hline 1 & case-1 & case-1 \\
\hline 2 & case-1 & case-2 \\
\hline 3 & case-1 & case-3 \\
\hline 4 & case-1 & case-4 \\
\hline 5 & case-2 & case-1 \\
\hline 6 & case-2 & case-2 \\
\hline 7 & case-2 & case-3 \\
\hline 8 & case-2 & case-4 \\
\hline 9 & case-3 & case-1 \\
\hline 10 & case-3 & case-2 \\
\hline 11 & case-3 & case-3 \\
\hline 12 & case-3 & case-4 \\
\hline 13 & case-4 & case-1 \\
\hline 14 & case-4 & case-2 \\
\hline 15 & case-4 & case-3 \\
\hline 16 & case-4 & case-4 \\
\hline
\end{tabular}




\begin{tabular}{|c|c|c|c|c|}
\hline \multirow[t]{2}{*}{ Plate no. } & \multirow[t]{2}{*}{ Approach } & \multicolumn{2}{|c|}{$\begin{array}{c}\text { Acceleration } \\
(\mathbf{m} / \mathbf{s} 2)\end{array}$} & \multirow{2}{*}{$\begin{array}{l}\text { Ratio } \\
(\mathbf{a} / \mathbf{b})\end{array}$} \\
\hline & & $\begin{array}{l}\text { Healthy } \\
\text { (a) }\end{array}$ & $\begin{array}{l}\text { Damaged } \\
\text { (b) }\end{array}$ & \\
\hline \multirow{4}{*}{1} & Experimental & 22.09 & 24.12 & 0.915 \\
\hline & SEAL (Exp) & 20.34 & 21.41 & 0.950 \\
\hline & FEM & 21.73 & 21.41 & 1.014 \\
\hline & SEAL (FEM) & 22.44 & 21.39 & 1.049 \\
\hline \multirow{4}{*}{2} & Experimental & 8.80 & 8.01 & 1.098 \\
\hline & SEAL (Exp) & 8.54 & 8.85 & 0.965 \\
\hline & FEM & 5.54 & 7.72 & 0.717 \\
\hline & SEAL (FEM) & 7.55 & 7.37 & 1.025 \\
\hline \multirow{4}{*}{3} & Experimental & 4.17 & 2.83 & 1.473 \\
\hline & SEAL (Exp) & 3.86 & 2.74 & 1.409 \\
\hline & FEM & 4.07 & 2.80 & 1.449 \\
\hline & SEAL (FEM) & 2.67 & 1.90 & 1.405 \\
\hline
\end{tabular}

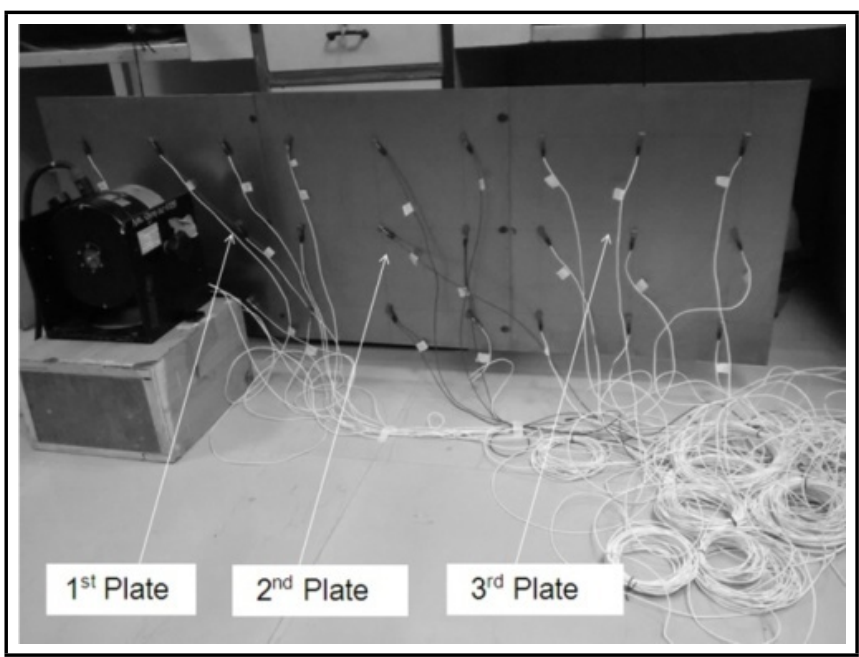

Figure 12. The experimental set-up (Combination-1).

combination 1 (three plates with all the spot-welds intact) and combination 2 (three plates with the last plate having one centre-weld damaged), with an excitation at the central point of the first plate has been predicted using statistical energy analysis-like approach. The codes required for carrying out the computations have been developed using MATLAB software.

The velocity responses have been predicted for the combination 1 shown in Fig. 12 and combination 2 shown in Fig. 14 by using the effective coupling factors obtained from the experimentation and finite element simulation, respectively. The predicted value for combination 1 has been compared with the results obtained from actual experimentation and finite element simulation in Figs. 13(a) to 13(c). The predicted value for combination 2 has been compared with the results obtained from actual experimentation and finite element simulation in Figs. 15(a) to 15 (c). The excitation frequency of $3000 \mathrm{~Hz}$ has been selected as the deterministic frequency for detection of damage for the combinations as listed out in Table 7 Table 8 shows the acceleration responses obtained for combination 1 (healthy) and combination 2 (damaged) in plate-1, plate-2 and plate-3 at an excitation frequency of $3000 \mathrm{~Hz}$. In practice, the acceleration responses would be measured. Acceleration response for each plate can be computed by multiplying the plate velocity with the frequency of excitation.

It has been observed from Table 8 that for combination- (a)

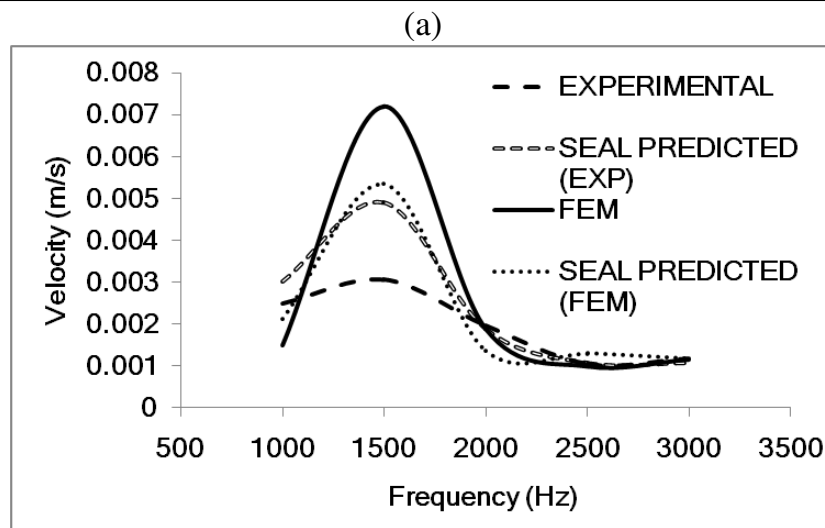

(b)

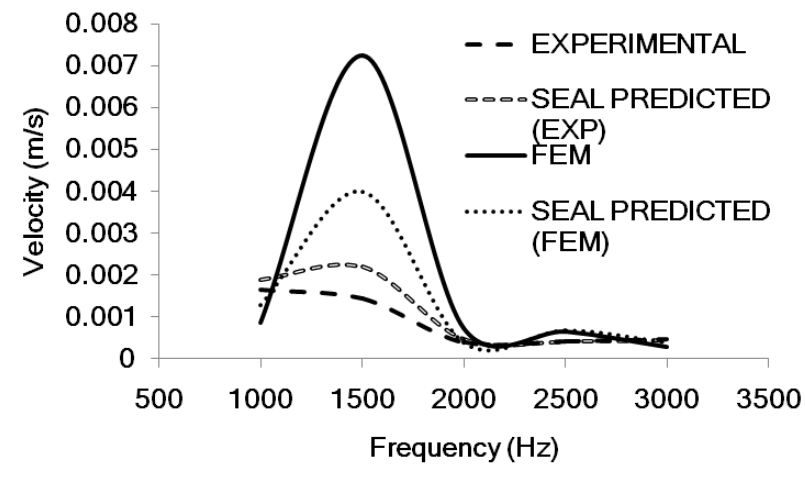

(c)

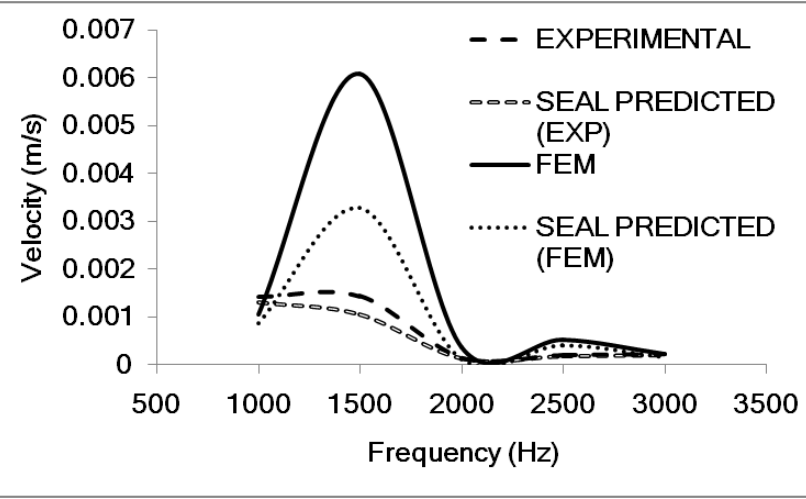

Figure 13. The velocity responses for Combination-1 (a) Plate 1, (b) Plate 2, and (c) Plate 3.

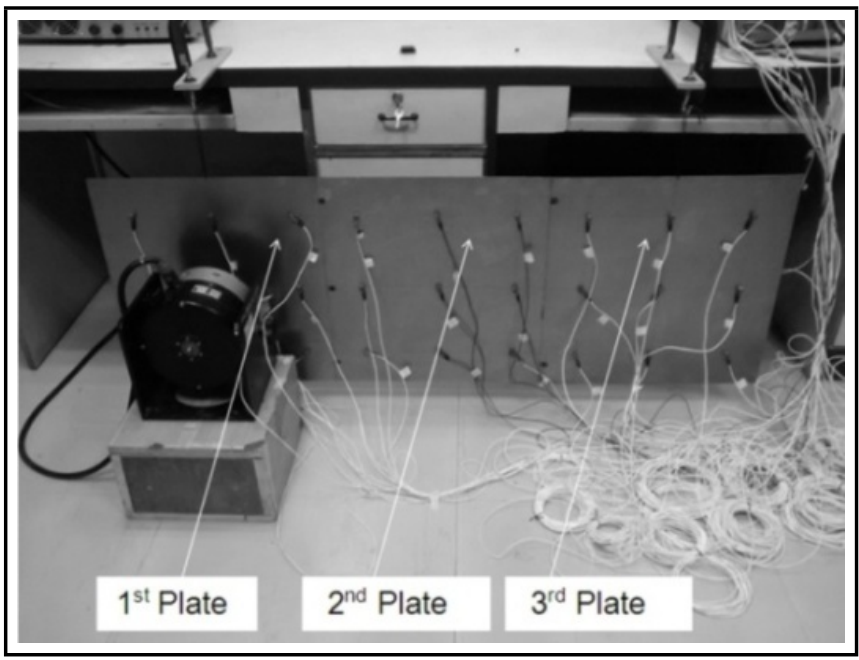

Figure 14. The experimental set-up (Combination-2). 


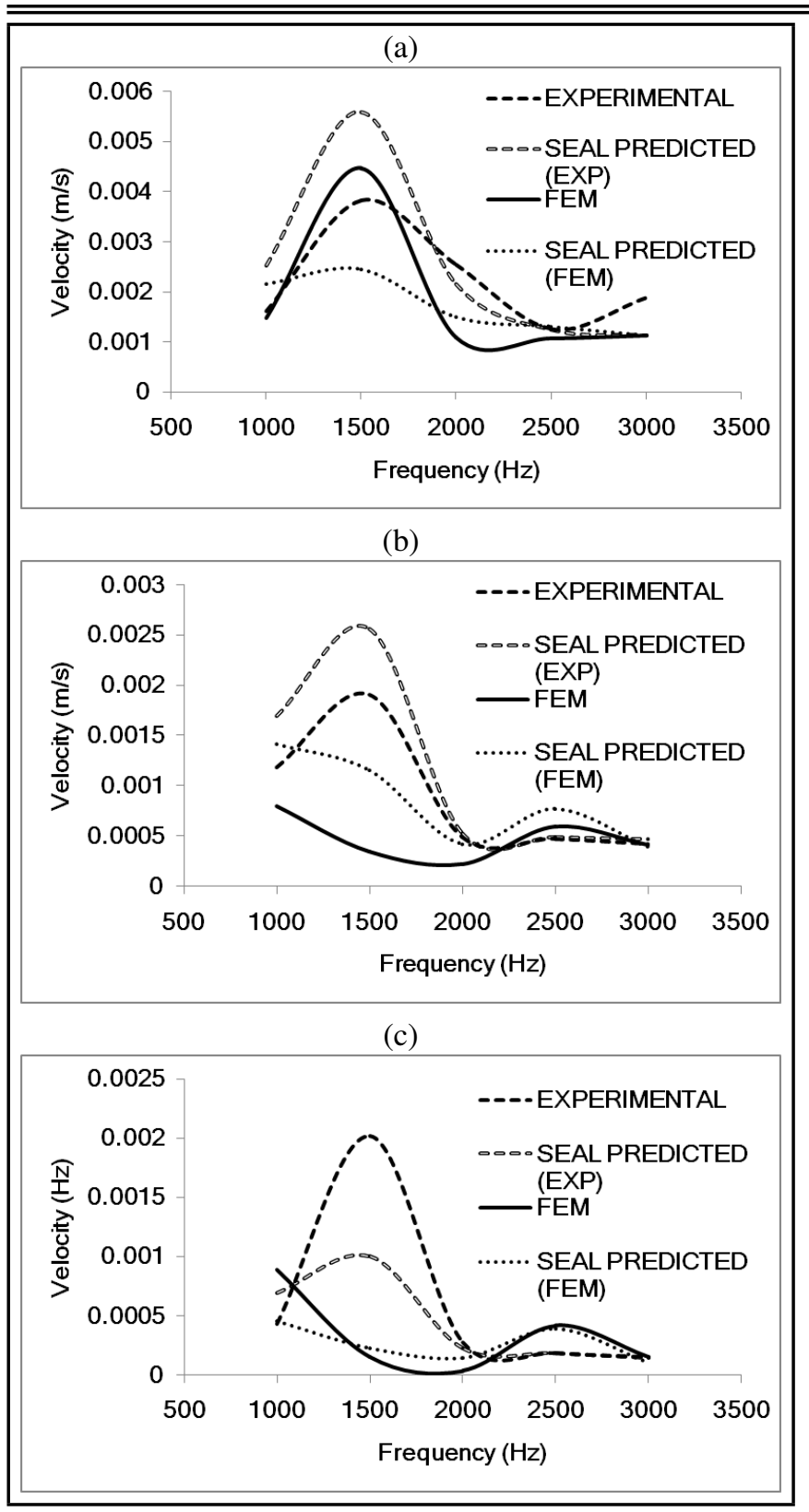

Figure 15. The velocity responses for Combination-2 (a) Plate 1, (b) Plate 2, and (c) Plate 3.

2 (Third plate connected to the second plate with the centre weld assumed to be damaged) the energy, velocity and consequently the acceleration response in Plate-3 (combination-2) is reduced in comparison to the values of the same in Plate- 3 for combination-1.

The values predicted using the SEAL approach is in close agreement with other approaches and has been further used to create a database bank of the expected acceleration responses for the remaining combinations of available sub-system cases using the apparent coupling factors as given in Tables 4 and 5 . The ratio of acceleration responses on each plate of combination 1 (healthy configuration) with the values obtained for the remaining combinations respectively has been used as the damage indicator as listed out in Table 9.

It has been seen that the values obtained from the actual FE simulation for plates joined by a single weld combinations (13, $14,15,16)$ are higher as compared to the SEAL predicted val- ues. In such cases, the ends of the plates away from the spotweld have large amplitudes vibrations that are limited in practical conditions during the experimental test, as compared to the finite element simulations. The SEAL predicted values obtained for the other combinations are in close agreement with the ones obtained from actual FE simulation. Such a simulated database bank could be used to identify the joint damage in a particular sub-system for further use.

\section{CONCLUSIONS}

The ease of computing responses and energies through power balance equations using an SEA-like approach as a simulation tool has been used to generate acceleration, velocity responses, and energies for an assembly of sub-systems with a known damage in one of the sub-systems. The reduction in the number of spot welds for sequentially coupled plates lead to reduction in the values of apparent coupling factors, energies, velocities, and an acceleration response of the subsequent plate following the damaged spot-weld joint. Proper FE modeling of spot-welded joints and incorporation of damping from experiments plays a critical role in the estimation of coupling factors using FEA. In case of highly complex configurations, experimental determination of the coupling factors for the basic sub-system may become inevitable. The excitation frequency selected, should represent a uniform energy density in a particular bandwidth fulfilling the assumptions in the energy balance equations in an SEA-like approach, which is obtained at higher frequencies due to higher modal density and modal overlap. The requirement of online response measurements and the need to obtain responses in a spatially averaged sense may increase the cost of set-up. The proposed SEAL based prediction approach can be used to generate a database of velocity/acceleration responses for various possibilities of sequentially coupled combinations of the basic cases, which can be effectively applied to locate the damaged joint in an assembly of subsystems for future use. The data generated can also be further utilized for optimal location of sensors and use in pattern recognition methods for damage detection.

\section{REFERENCES}

1 Doebling, S.W., Farrar, C.R., and Prime, M.B. A summary review of vibration-based damage identification methods, The Shock and Vibration Digest, 30 (2), 91-105, (1998). https://dx.doi.org/10.1177/058310249803000201

2 López-Díez, J.,Torrealba, M.,Güemes, A., and Cuerno, C. Application of Statistical Energy Analysis for damage detection in spacecraft structures, Key Engineering Materials, 293-294, 525-532, (2005). https://dx.doi.org/10.4028/www.scientific.net/kem.293294.525

3 Whittingham, B., Herszberg, C., and Chiu, W.K. Disbond detection in adhesively bonded composite structures using vibration signatures. Journal of Composite Structures, 75, 351363, (2006). https://dx.doi.org/10.1016/j.compstruct.2006.04.055 
Table 9. Ratio of acceleration responses (Excitation Frequency-3000 Hz).

\begin{tabular}{|c|c|c|c|c|c|c|c|c|c||}
\hline \multirow{2}{*}{ Combination } & \multicolumn{3}{|c|}{ Seal Predicted } & \multicolumn{3}{c|}{ Seal Predicted (FEM) } & \multicolumn{3}{c|}{ FEM } \\
\cline { 2 - 11 } & Plate-1 & Plate-2 & Plate-3 & Plate-1 & Plate-2 & Plate-3 & Plate-1 & Plate-2 & Plate-3 \\
\hline 3 & 0.99 & 0.95 & 1.54 & 0.99 & 0.97 & 1.47 & 0.99 & 1.02 & 1.23 \\
\hline 4 & 0.99 & 0.95 & 1.84 & 0.99 & 0.95 & 2.84 & 0.99 & 0.92 & 2.08 \\
\hline 5 & 0.96 & 1.33 & 1.33 & 0.97 & 1.34 & 1.34 & 0.93 & 1.21 & 1.21 \\
\hline 6 & 0.96 & 1.28 & 1.76 & 0.97 & 1.30 & 1.78 & 0.95 & 1.35 & 1.84 \\
\hline 7 & 0.96 & 1.26 & 2.03 & 0.97 & 1.29 & 1.97 & 0.90 & 1.26 & 2.67 \\
\hline 8 & 0.96 & 1.25 & 2.43 & 0.97 & 1.27 & 3.79 & 0.88 & 0.83 & 2.09 \\
\hline 9 & 0.94 & 1.54 & 1.54 & 0.96 & 1.47 & 1.47 & 0.99 & 1.47 & 1.65 \\
\hline 10 & 0.94 & 1.48 & 2.03 & 0.96 & 1.43 & 1.97 & 1.00 & 1.29 & 2.48 \\
\hline 11 & 0.94 & 1.46 & 2.35 & 0.96 & 1.43 & 2.17 & 0.99 & 1.54 & 3.25 \\
\hline 12 & 0.94 & 1.44 & 2.81 & 0.96 & 1.40 & 4.18 & 0.99 & 2.2 & 6.53 \\
\hline 13 & 0.93 & 1.84 & 1.84 & 0.94 & 2.84 & 2.84 & 1.03 & 8.12 & 5.79 \\
\hline 14 & 0.93 & 1.77 & 2.43 & 0.94 & 2.77 & 3.79 & 1.03 & 8.48 & 5.43 \\
\hline 15 & 0.93 & 1.75 & 2.81 & 0.94 & 2.75 & 4.18 & 1.03 & 5.39 & 6.52 \\
\hline 16 & 0.93 & 1.73 & 3.36 & 0.94 & 2.70 & 8.04 & 1.03 & 5.79 & 14.8 \\
\hline
\end{tabular}

4 Giurgiutiu, V., and Zagrai, A. Damage detection in thin plates and aerospace structures with the electro-mechanical impedance method, Structural Health Monitoring, 4, 99-118, (2005). https://dx.doi.org/10.1177/1475921705049752

5 Samanta, B., Al-Balushi, K. R., Al-Araimi,S. A. Artificial neural networks and support vector machines with genetic algorithm for bearing fault detection, Engineering Applications of Artificial Intelligence, 16, 657-665, (2003). https://dx.doi.org/10.1016/j.engappai.2003.09.006

6 Worden, K., and Lane, A. J. Damage identification using support vector machines, Smart Materials and Structures, 10, 540547, (2001). https://dx.doi.org/10.1088/0964$1726 / 10 / 3 / 317$

7 Pankaj, Achuthan. C., Sastry, S., and Murigendrappa, S.M. A comparison of different methods for determination of coupling factor and velocity response of coupled plates, Journal of Vibro-engineering, 15 (4),1885-1897, (2013).

8 Yap, F. F., and Woodhouse, J. Investigation of damping effects on statistical energy analysis of coupled structures, Journal of Sound and Vibration, 197 (3), 351-371, (1996). https://dx.doi.org/10.1006/jsvi.1996.0536

9 Kuratani, F.,Matsubara, K., and Yamauchi, T. Finite Element Model for Spot Welds Using Multi-Point Constraints and its dynamic characteristics, SAE International Journal of Passenger Cars - Mechanical Systems, 4 (2),1311-1319, (2011). https://dx.doi.org/10.4271/2011-01-1697

10 Pankaj, Achuthan. C., and Murigendrappa,S.M. Determination of coupling factors for spot welded plates, International Conference on Theoretical, Applied, Computational and Experimental Mechanics, IIT-Kharagpur, (2014).
11 Fredo, C. R, SEA-like approach for the derivation of energy flow coefficients with a finite element model, Journal of Sound and Vibration, 199 (4), 645-666, (2014). https://dx.doi.org/10.1006/jsvi.1996.0634

12 Thite, A. N., and Mace, B. R. Robust estimation of coupling loss factors from finite element analysis, Journal of Sound and Vibration, 303, 814-831, (2007). https://dx.doi.org/10.1016/j.jsv.2007.02.004

13 Bies, D. A., and Hamid, S. In situ determination of loss and coupling loss factors by the power injection method, Journal of Sound and Vibration, 70,187-204, (1980). https://dx.doi.org/10.1016/0022-460x(80)90595-7

14 De-Langhe K., and Sas, P. Statistical analysis of the power injection method, Journal of the Acoustical Society of America, 100, 291-303, (1996). https://dx.doi.org/10.1121/1.415915

15 Bloss, B., and Rao, M. D. Measurement of damping in structures by the power input method, Experimental Techniques, 26, 30-33, (2002). https://dx.doi.org/10.1111/j.1747-1567.2002.tb00066.x

16 Palmonella, M., Friswell, M.I., Mottershead, J.E., Lees, A.W. Finite element models of spot welds in structural dynamics: review and updating, Computers and Structures, 83, 648661, (2005). https://dx.doi.org/10.1016/j.compstruc.2004.11.003

17 Palmonella, M., Friswell, M.I., Mottershead, J.E., Lees, A.W. Guidelines for the implementation of the CWELD and ACM2 spot weld models in structural dynamics, $F i$ nite Elements in Analysis and Design, 41, 193210, (2004). https://dx.doi.org/10.1016/j.finel.2004.04.003 